\title{
A FIA procedure for enzymatic determination of high glucose concentrations. Application to parenteral solutions analysis
}

\author{
E. Barrado ${ }^{1}$, M.H. Vela ${ }^{1}$, R.A.S. Lapa ${ }^{2, *}$ and J.L.F.C. Lima ${ }^{2}$ \\ ${ }^{1}$ Departamento de Química Analítica, Facultad de Ciencias, Prado de la Magdalena s/n, \\ Universidad de Valladolid, 47005 Valladolid, España \\ ${ }^{2}$ CEQUP/Departamento de Química-Física, Faculdade de Farmácia, Rua Anibal Cunha 164, \\ Universidade de Porto, 4050 Porto, Portugal
}

\begin{abstract}
A flow injection system for the determination of high levels of glucose in parenteral solutions based on amperometric detection of hydrogen peroxide produced in the glucose oxidase reaction was developed. The determinations were made without any sample pre-treatment. The flow injection manifold includes two dialysis units to perform dilution of the samples and to maintain the enzyme in a closed re-circulation loop. Due to the hydrodynamic characteristics of the analytical system, the variables were optimized using a parameter design of Taguchi. Under optimal conditions, a linear response for glucose concentrations, between 0.1 and $1.0 \mathrm{M}$ was achieved. A good reproducibility (r.s.d. $<3 \%$ ) and a sampling rate of 30 determinations/hour were observed. The results obtained are in a good agreement with those obtained using the spectrophotometric enzymatic method.
\end{abstract}

Keywords. Flow injection analysis - amperometry - glucose - parenteral solutions - Taguchi parameter design - glucose oxidase reaction.

\section{Introduction}

Enzyme-based procedures using flow injection analysis (FIA) systems are one of the most widely used methods for the estimation of biological substrates. Several enzymatic techniques for the determination of glucose are actually available and include the use of glucose oxidase. This enzyme is highly specific for the oxidation of $\beta$-D-glucose to gluconate and hydrogen peroxide [1]. Most commercially available preparations of the enzyme also contain the enzyme mutarotase which catalyses transformation from alpha to beta form. Reaction products may be determined spectrophotometrically either by direct estimation of the NADH produced using NAD-glucose dehydrogenase or indirectly, by reacting the hydrogen peroxide to produce a colored product [2-4]. Other possibilities are the detection of electroactive products such as $\mathrm{H}_{2} \mathrm{O}_{2}$, generally performed using solid electrodes such as platinum or glassy carbon [5-7] modified electrodes [8-9], or biosensors [10].

In continuous flow techniques, several strategies have been undertaken to adapt quantification methods to the range of sample concentrations. Dialysis membranes have proved to be an adequate alternative for the estimation of highly concentrated sample [11]. The reduction in cost of the determination is generally associated with reduced enzyme consumption. This has been achieved by immobilization of the enzymes in the system prior to the detector or in the detec- tor itself [12-25] using a closed-loop as proposed by Roehrig et al. [26]. Alternatively, the enzyme is trapped in one of the channels of the dialysis membrane [27].

In this paper, an enzymatic determination of glucose in parenteral solutions using an FIA system is described. The system is based on the amperometric detection of $\mathrm{H}_{2} \mathrm{O}_{2}$ using a platinum electrode. In an effort to obtain a simple, rapid, stable and cost effective method, two dialysis membranes were included. The first membrane enables samples to be diluted due to the low rate of transport across the membranes of the flow system. The second membrane is introduced to restrict the enzyme to a closed circuit and reduce its consumption. Optimization of hydrodynamic variables was performed according to a parameter design of Taguchi. This design determines the conditions, which are insensitive to the variability of the different sample preparations [2829].

\section{Materials and methods}

\section{Reagents and solutions}

Analytical grade reagents were used without further purification throughout. The solutions were prepared with distillated and deionized water (specific conductivity $<0.1 \mu \mathrm{S}$ $\left.\mathrm{cm}^{-1}\right)$.

* Correspondence and reprints.

Received August 25, 1998; revised February 26, 1999; accepted February 28, 1999 


\section{Original articles}

The enzymes were obtained by reconstitution of a lyophilized preparation of glucose oxidase from Aspergillus Niger (Boehringer Mannheim GmbH 646423).

D-glucose was obtained from Merck (Ref. 8337) and dextran from Sigma (D-9260).

For glucoses determination by conventional methodology was made using Boehringer UV-Kit (Ref. 716251) [30]. Samples provided from Paracelcia were previously diluted and assayed according to the manufacturer.

\section{Equipment}

A 4-channel Gilson Minipuls-3 peristaltic pump fitted with Gilson tubes ensured the flow of solutions. Samples were introduced into the carrier flow using a 4-way, rotary injection valve (Rheodyne 5020). The components of the FIA system were linked using Omnifit Teflon tubing (0.8-mm internal diameter). Joints were secured with Gilson connectors. Connectors, pulse dampers [31] and dialyzers [32] were laboratory-manufactured using Perspex. The dialysis membranes used in dialysis units were supplied by Tecator (Ref. 5588 0002). The dialysis channels were $2 \mathrm{~mm}$ wide and 7.0 and $10.5 \mathrm{~cm}$ long respectively.

Amperometric determinations were performed using a potentiostat/galvanostat EG\&G PAR Model 273A, equipped with Model 270/250 Research Electrochemical Software v. 4.10. The flow cell was a "wall-jet" type Methrom 656 electrochemical detector, with a 3-electrode system comprised of a $\mathrm{Pt}$ working electrode, an $\mathrm{Ag} / \mathrm{AgCl}(3 \mathrm{M} \mathrm{KCl})$ reference electrode and gold auxiliary electrode.

For the conventional method of glucose determination, the absorbance of samples at $510 \mathrm{~nm}$ in $1 \mathrm{~cm}$ cuvettes was determined using a Philips PU8710 spectrophotometer.

\section{Optimization procedure}

The Taguchi parameter design (also called parameter design) [28-29] consisting in the deliberate introduction of changes in the experiment in order to evaluate their effects on the searched response. The TPD differentiates between control factors and noise or incontrollable factors and treats separately by means of special design matrices called "Ortogonal Arrays" (OA). Columns (corresponding to factors and their interactions) and rows (corresponding to trials) of an OA are arranged in a fixed way indicating the combination of factor levels in each experiment to be run, and allowing the simultaneous evaluation of several parameters with the minimum number of trials.

\section{Results and discussion}

The proposed method for glucose determination is based on the appearance of hydrogen peroxide as a consequence of the reaction:
$\beta$-D-glucose $+\mathrm{O}_{2}+\mathrm{H}_{2} \mathrm{O} \stackrel{\mathrm{GO}_{\mathrm{x}}}{\longrightarrow}$ D-Gluconate $+\mathrm{H}^{+}+\mathrm{H}_{2} \mathrm{O}_{2}$.

A preliminary study was performed by direct measurement of the $\mathrm{H}_{2} \mathrm{O}_{2}$ in batch procedures and subsequently in the FIA system, to evaluate the optimal conditions, namely the potential required to detect $\mathrm{H}_{2} \mathrm{O}_{2}$ under the present conditions. It was found that the maximum signal was reached at $\mathrm{pH} 13$ and $0.6 \mathrm{~V}$ (vs. $\mathrm{AgCl} / \mathrm{Ag}$ ) as proposed in the literature $[5,33]$.

Taking into account that optimal conditions for peroxide determination is under alkaline conditions and the most adequate $\mathrm{pH}$ for the enzyme reaction is 7.0, the enzyme is dissolved and maintained in phosphate buffer in the closedcircuit while detection is performed at $\mathrm{pH} \mathrm{13.} \mathrm{Concerning}$ the stability of the enzyme in the closed circuit it was verified that is possible assays after 200 consecutive injections, with no major variations in response peak height. Hence, the only limitation in the use of the enzyme is the stability period of the reconstituted lyophilisate.

\section{Manifold}

The schematic representation of the developed FIA system for glucose determination in parenteral solutions is shown in figure 1 .

A $20 \mathrm{~mL}$ aliquot of glucose oxidase with an activity of $15 \mathrm{U} / \mathrm{mL}$ in $0.2 \mathrm{M}$ phosphate buffer $\mathrm{pH} \mathrm{7,} \mathrm{is} \mathrm{introduced} \mathrm{into}$ the closed circuit (Fig. 1). The untreated sample $(100 \mu \mathrm{L})$ is then injected into carrier solution $\mathrm{C}(0.1 \mathrm{M} \mathrm{NaOH}$ and $0.1 \mathrm{M} \mathrm{NaCl}$ ). This carrier flew across the dialysis membrane and allows the adjustment of the glucose concentration to the optimum value, using the DM-1 dialysis membrane. This membrane separates the two parallel flows, C and D. C flow, which contains the sample, is discarded after crossing the DM-1 membrane. D flow, with a similar composition, collects the species to be determined and transports them to the second dialysis membrane (DM-2), were the enzymatic reaction takes place.

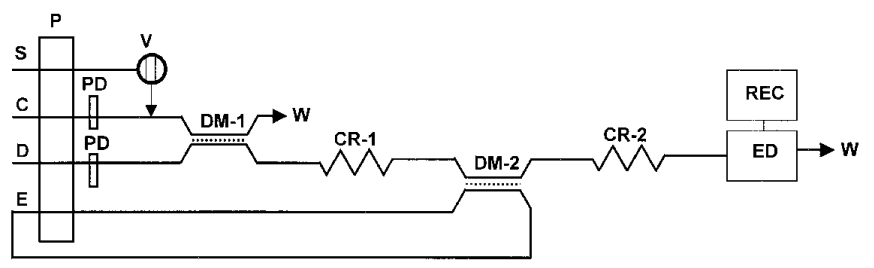

Fig. 1. Flow injection manifold for glucose determination: $S$, sample; C, carrier; D, dilutor; E: enzyme; CFR, DFR $=1.3 \mathrm{~mL} / \mathrm{min}$; $\mathrm{EFR}=0.3 \mathrm{~mL} / \mathrm{min} ; \mathrm{P}$, peristaltic pump; $\mathrm{V}$, injection valve $(100 \mu \mathrm{L})$; PD pulse damper; CR-1 $(10 \mathrm{~cm})$ and CR-2 $(15 \mathrm{~cm})$, coil lengths; DM-1 $(7.0 \mathrm{~cm})$ and DM-2 $(10.5 \mathrm{~cm})$, dialysis units; ED, electrochemical detector; REC, recorder; W, waste. 


\section{Original articles}

\section{Optimization of flow system hydrodynamic and geometric variables}

A Taguchi parameter design [28] was used to optimize the FIA system. The variables used were flow rate of the carrier in $\mathrm{mL} / \mathrm{min}$ (FRC), flow rate of the dilutor in $\mathrm{mL} / \mathrm{min}$ (FRD), flow rate of the enzyme in $\mathrm{mL} / \mathrm{min}$ (FRE), injection volume in $\mu \mathrm{L}$ (IV), coil length before enzyme reaction (CLB) and coil length after enzyme reaction (CLA), in $\mathrm{cm}$. Ionic strength was chosen as the "noise factor" [29] and expressed as the concentration of $\mathrm{NaCl}(\mathrm{M})$ insensitive to the possible different electrolyte concentrations present in each parenteral solution.

Table I shows the control factors and their levels. Seven factors with two levels each one, were tested, which corresponds to seven degrees of freedom, using a $\mathrm{L}_{8}\left(2^{7}\right)$ orthogonal array.

The response values (Tab. II) lists the different combinations of the factors tested at each noise level and the Ip $(\mu \mathrm{A})$ values obtained (last 2 columns). Statistical analysis of the data showed that the response was mostly affected by the carrier flow rate, followed by the length of the reactor 2 .

The response curves obtained due to changes in factors and in the noise level demonstrated the effects of the FRC and CLA and using these conditions the most intense response was predicted to be $\mathrm{FRC}_{1}, \mathrm{FRD}_{1}, \mathrm{FRE}_{1}, \mathrm{CLB}_{1}$ and $\mathrm{CLA}_{2}$. Under these conditions, both injection volumes tested would be appropriate.

Table III shows the pooled ANOVA of the signal-to-noise analysis. It may be seen that the FRC factor makes an $82.78 \%$ contribution to response variability and the remaining factors (FRD, FRE and CLA) contribute by approximately $5 \%$. Residual contribution was of the order of $0.92 \%$ confirming the appropriate choice of control factors.

With these data it was possible to conclude that, for a fixed dilution set by the first dialysis unit, the conditions offering the maximum response signal, maximum signal/noise ratio and greatest insensitivity relatively to noise corresponds to the following combination: $\mathrm{FRC}_{1}$ (1.3 $\mathrm{mL} / \mathrm{min}), \mathrm{FRD}_{1}(1.3 \mathrm{~mL} / \mathrm{min}), \mathrm{EFR}_{1}(0.3 \mathrm{~mL} / \mathrm{min}), \mathrm{IV}_{2}$ $(100 \mu \mathrm{L}), \mathrm{CLB}_{1}(10 \mathrm{~cm})$ and $\mathrm{CLA}_{1}(15 \mathrm{~cm})$. The latter factor was chosen since it affords the greatest sampling rate. Ionic strength was fixed at $0.1 \mathrm{M} \mathrm{NaCl}$, although it does not significantly affect the response.

The theoretical prediction by Taguchi design was confirmed experimentally. A peak height of $0.285 \mu \mathrm{A}$ was obtained for the same concentration of glucose used over the entire optimization process and a sampling rate of 30 determinations/hour. The calibration curve obtained under these conditions allows the determination of glucose concentrations in the range 0.1 to $1 \mathrm{M}\left(y=0.7909 x, R^{2}=0.9911\right)$.

\section{Determination of glucose in parenteral solutions}

Table IV shows the results obtained using 8 samples of parenteral solutions commonly found on the Portuguese and
Table I. Factors and levels for optimization.

\begin{tabular}{llcc}
\hline Notation & \multicolumn{1}{c}{ Factor } & Level 1 & Level 2 \\
\hline FRC & Flow rate of Carrier $(\mathrm{mL} / \mathrm{min})$ & 1.3 & 2.6 \\
FRD & Flow rate of Dilutor $(\mathrm{mL} / \mathrm{min})$ & 1.3 & 2.6 \\
FRE & Flow rate of the Enzyme $(\mathrm{mL} / \mathrm{min})$ & 0.3 & 0.6 \\
IV & Injection volume $(\mu \mathrm{L})$ & 50 & 100 \\
CLB & Coil Length before $(\mathrm{cm})$ & 10 & 50 \\
CLA & Coil length after $(\mathrm{cm})$ & 15 & 40 \\
$\mathrm{~N}$ & Noise $(\mathrm{NaCl}, \mathrm{mol} / \mathrm{L})$ & 0.025 & 0.15 \\
\hline
\end{tabular}

Table II. Experimental L8 $\left(2^{7}\right)$ orthogonal array with a two-level noise factor $(\mathrm{NaCl})$. Two last columns show the $\operatorname{Ip}(\mu \mathrm{A})$ obtained in each trial at each noise level.

\begin{tabular}{|c|c|c|c|c|c|c|c|c|}
\hline \multirow[b]{2}{*}{ Trial } & \multirow[b]{2}{*}{$F R C$} & \multicolumn{3}{|c|}{ Factor levels } & \multirow[b]{2}{*}{$C L B$} & \multirow[b]{2}{*}{$C L A$} & \multicolumn{2}{|c|}{$\operatorname{Ip}(\mu A)$} \\
\hline & & $F R D$ & $F R E$ & $I V$ & & & $N_{1}$ & $\mathrm{~N}_{2}$ \\
\hline \multirow[t]{2}{*}{1} & 1 & 1 & 1 & 1 & 1 & 1 & 0.149 & 0.151 \\
\hline & & & & & & & 0.135 & 0.159 \\
\hline \multirow[t]{2}{*}{2} & 1 & 1 & 1 & 2 & 2 & 2 & 0.167 & 0.210 \\
\hline & & & & & & & 0.128 & 0.219 \\
\hline \multirow[t]{2}{*}{3} & 1 & 2 & 2 & 1 & 1 & 2 & 0.108 & 0.170 \\
\hline & & & & & & & 0.094 & 0.181 \\
\hline \multirow[t]{2}{*}{4} & 1 & 2 & 2 & 2 & 2 & 1 & 0.139 & 0.108 \\
\hline & & & & & & & 0.082 & 0.075 \\
\hline \multirow[t]{2}{*}{5} & 2 & 1 & 2 & 1 & 2 & 1 & 0.043 & 0.067 \\
\hline & & & & & & & 0.048 & 0.066 \\
\hline \multirow[t]{2}{*}{6} & 2 & 1 & 2 & 2 & 1 & 2 & 0.076 & 0.064 \\
\hline & & & & & & & 0.089 & 0.053 \\
\hline \multirow[t]{2}{*}{7} & 2 & 2 & 1 & 1 & 2 & 2 & 0.075 & 0.074 \\
\hline & & & & & & & 0.048 & 0.079 \\
\hline
\end{tabular}

Spanish markets. Samples were analyzed without previous dilution or other treatment. Data shown in the tables represent mean values of 5 determinations corresponding to 5 consecutive sample injections.

Application of the Student's paired t-test to compare both sets of results indicates that $t$ for the difference population is 0.89 . This value is less than the critical figure for a $p$ value of 0.05 and 7 degrees of freedom (2.365). It may, thus, be concluded that there are no significant differences between the proposed method and the batch method at a confidence level of $95 \%$.

\section{Conclusions}

The FIA system developed for the determination of high glucose concentrations such as those of parenteral solutions 
Table III. Pooled ANOVA of the signal/noise analysis.

\begin{tabular}{|c|c|c|c|c|c|c|c|}
\hline Source & Pool & $\begin{array}{l}\text { Degree of } \\
\text { freedom }\end{array}$ & $\begin{array}{l}\text { Sum of } \\
\text { squares }\end{array}$ & Variance & $\begin{array}{l}\text { Variance } \\
\text { ratio }(F)\end{array}$ & $\begin{array}{c}\text { Pooled Sum } \\
\text { of squares }\end{array}$ & $\begin{array}{c}\text { Contribution } \\
(\%)^{a}\end{array}$ \\
\hline FRC & {$[\mathrm{N}]$} & 1 & 93.96 & 93.96 & 631.15 & 93.81 & 82.78 \\
\hline FRD & {$[\mathrm{N}]$} & 1 & 6.26 & 6.26 & 42.07 & 6.11 & 5.40 \\
\hline FRE & {$[\mathrm{N}]$} & 1 & 5.34 & 5.34 & 35.86 & 5.19 & 4.58 \\
\hline IV & {$[\mathrm{Y}]$} & 1 & 0.25 & 0.25 & & & \\
\hline CLB & {$[\mathrm{Y}]$} & 1 & 0.18 & 0.18 & & & \\
\hline CLA & {$[\mathrm{N}]$} & 1 & 7.31 & 7.31 & 49.12 & 7.16 & 6.32 \\
\hline Error & {$[\mathrm{Y}]$} & 1 & 0.02 & 0.02 & & & \\
\hline Residual & & 3 & 0.45 & 0.15 & & 1.04 & 0.92 \\
\hline Total & & 7 & 113.32 & 16.18 & & & 100.00 \\
\hline
\end{tabular}

${ }^{a}$ Contribution is defined as $100 \bullet$ (pooled sum of squares/total sum of squares).

Table IV. Comparison of results obtained for the determination of glucose in parenteral solutions by FIA and batch methods (average of 5 determinations).

\begin{tabular}{llccc}
\hline Commercial Name & Label & Batch $(U$ V-Vis), $M$ & FIA, M & \% Recovery \\
\hline Neodextril 70 in Dextrose & 0.277 & $0.300 \pm 0.018$ & $0.306 \pm 0.070$ & 108.3 \\
Glucosteril 5\% in S.F. & 0.277 & $0.263 \pm 0.012$ & $0.270 \pm 0.048$ & 97.5 \\
Glucosteril 5\% in NaCl 0.15\% & 0.277 & $0.272 \pm 0.006$ & $0.266 \pm 0.020$ & 96.0 \\
Soro 210 & 0.183 & $0.183 \pm 0.006$ & $0.185 \pm 0.016$ & 101.1 \\
Neodextril 40 in Glucose & 0.277 & $0.276 \pm 0.046$ & $0.273 \pm 0.028$ & 98.6 \\
Glucosteril 5\% & 0.277 & $0.282 \pm 0.014$ & $0.271 \pm 0.012$ & 97.8 \\
Neodextril 70 in Dextrose & 0.377 & $0.323 \pm 0.011$ & $0.338 \pm 0.023$ & 140.1 \\
Glucosteril 10\% & 0.555 & $0.708 \pm 0.038$ & $0.721 \pm 0.053$ & 129.9 \\
\hline
\end{tabular}

avoiding the need for pre-treatment allow a sampling rate of 30 determinations/hour and the results were comparable to those obtained using conventional batch methods.

The use of the re-circulating enzyme (glucose oxidase) minimizes consumption and reduces costs. Furthermore, the use of a dialysis strategy permits measurement of glucose at considerably high concentration without loss of sensitivity or response time and is able to eliminate interference in-situ.

The strategy used in the optimization of the control factors, based on Taguchi method, presents advantages concerning its insensitivity to noise (variation in ionic strength of the sample).

The proposed method present attractive characteristics such could be completely automated, have a low cost and could be easily implemented in routine laboratories namely in control of production of parenteral solutions.

\section{Acknowledgements}

The authors wish to thank the JNIC (Project PBICT/P/QUI/2165/95), to the DG12 HSMU (contract
CIPA-CT93-0106) and to Consejería de Educación y Cultura de la Junta de Castilla y León (Project VA31/99) for their financial support.

\section{References}

1. Raba, J.; Mottola, M. A. Crit. Rev. Anal. Chem. 1995, 25, 142.

2. Orsonneau, J. L.; Meflah, K.; Lustenberger, P.; Cornu, G.; Bernard, S. Clin. Chim. Acta 1982, 125, 185-192.

3. Fujita, I.; Mori, M.; Toyoda; Matsuo, T. Anal. Sci. 1994, 10, 827-830.

4. Wilson, R. Anal. Lett. 1991, 24, 1983-2003.

5. Amine, A.; Palleschi, G. Electroanalysis 1995, 7, 785-787.

6. Matsubara, C. J. Flow Injection Anal. 1995, 12, 23-34.

7. Wollenberger, U.; Bogdanovskaya, V.; Bobrin, S.; Scheller, F.; Tarasevich, M. Anal. Lett. 1990, 23, 1795-1808.

8. Csoregi, E.; Gorton, L.; Marko-Varga, G. Electroanalysis, 1994, 6, 925-933.

9. Karyakin, A. A.; Karyakina, E. E.; Schuhmann, W.; Schmidt, H. L.; Varfolomeyev, S.D. Electroanalysis 1994, 6, 821-829.

10. Von Woedtke, T. U.; Fischer; Abel, P. Biosens. Bioelectron. 1994, 9, 65-71. 


\section{Original articles}

11. van-Staden, J. F. Fresenius' J. Anal. Chem. 1995, 352, 271302.

12. Scheper, T. H.; Hilmer, J. M.; Lammers, F.; Mueller, C.; Reinecke, M. J. Chromatogr. A 1996, 725, 3-12.

13. Hall, C. E.; Datta, D.; Hall, E. A. H. Anal. Chim. Acta 1996, $323,87-96$

14. Silber, A.; Hampp, N.; Schuhmann, W. Biosens. Bioelectron. 1996, 11, 215-223.

15. Trojanowicz, M.; Geschke, O.; Krawczynski-vel-Krawczyk, T.; Cammann, K. Sens. Actuators 1995, B28, 191-199.

16. Kiba, N.; Itagaki, A.; Fukumura, S.; Saegusa, K.; Furusawa, M. Anal. Chim. Acta. 1997, 354, 205-210.

17. Karyakin, A. A.; Karyakina, E. E.; Gorton, L. Talanta 1996, 43, 1597-1606.

18. Csoregi, E.; Laurell, T.; Katakis, I.; Heller, A.; Gorton, L. Mikrochim. Acta 1995, 121, 31-40.

19. Wang, J.; Fang, L.; Lopez, D.; Tobias, H. Anal. Lett. 1993, 26, 1819-1830.

20. Trojanowicz, M.; Matuszewski, W., Podsiadla, M. Biosens. Bioelectron. 1990, 5, 149-156.

21. Toei, J. Fresenius' Z. Anal. Chem. 1988, 332, 167-17.

22. Sanghera, G.S. Anal. Proc. 1988, 25, 108-110.
23. De-Alwis, U.; Hill, B. S.; Meiklejohn, B. I.; Wilson, G. S. Anal. Chem. 1987, 59, 2688-2691.

24. Thompson, R. Q.; Crouch, S. R. Anal. Chim. Acta. 1984, 159, 337-342.

25. Kiba, N.; Tomiyasu, T.; Furusawa, M. Talanta 1984, 31, 131132.

26. Roehrig, P.; Wolff, C. M.; Schwing, J. P. Anal. Chim. Acta 1983, 153, 181-190.

27. Araújo, A. N.; Lima, J. L. F. C.; Saraiva, M. L. M. F. S.; Zagatto, E. A. G. A. Am. J. Enol. Vit. 1997, 48, 428-432.

28. Taguchi, G. "System of Experimental Design", Vols. I and II, A.S.I.I. McGraw- Hill, 1991, N.Y.

29. Ross, P. J. "Taguchi Techniques for Quality Engineering", McGraw-Hill, 1988, N.Y.

30. Trinder, P. Ann. Clin. Biochem. 1969, 6, 24-28.

31. Alegret, S.; Alonso, J.; Bartrolí, J.; Machado, A. A. S. S.; Lima, J. L. F. C.; Paulís, J. M. Quím. An. 1987, 6, 278-292.

32. Lima, J. L. F. C.; Rangel, A. O. S. S.; Roque da Silva, M. M. S. At. Spectroscopy 1991, 12, 204-206.

33. Yao, T.; Satomura, M.; Nakahara, T. Anal. Chim. Acta 1994, 296, 271-276.

* Correspondence and reprints.

Received October 27, 1998; revised February 19, 1999; accepted February 25, 1999. 